\title{
Acute heart failure with and without acute coronary syndrome: clinical correlates and prognostic impact (From the HEARTS registry)
}

Hussam AlFaleh ${ }^{1}$, Abdelfatah A. Elasfar ${ }^{2}$, Anhar Ullah¹, Khalid F. AlHabib ${ }^{1}$, Ahmad Hersi ${ }^{1}$, Layth Mimish'3, Ali Almasood ${ }^{4}$, Saleh Al Ghamdi', Abdullah Ghabashi', Asif Malik', Gamal A. Hussein², Mushabab Al-Murayeh', Ahmed Abuosa ${ }^{10}$, Waleed Al Habeeb ${ }^{1}$ and Tarek S. Kashour ${ }^{1,11^{*}}$

\begin{abstract}
Background: Little is know about the outcomes of acute heart failure (AHF) with acute coronary syndrome (ACS-AHF), compared to those without ACS (NACS-AHF).

Methods: We conducted a prospective registry of AHF patients involving 18 hospitals in Saudi Arabia between October 2009 and December 2010. In this sub-study, we compared the clinical correlates, management and hospital course, as well as short, and long-term outcomes between AHF patients with and without ACS.

Results: Of the 2609 AHF patients enrolled, $27.8 \%$ presented with ACS. Compared to NACS-AHF patients, ACS-AHF patients were more likely to be old males (Mean age $=62.7$ vs. 60.8 years, $p=0.003$, and $73.8 \%$ vs. $62.7 \%, p<0.001$, respectively), and to present with De-novo heart failure (56.6 \% vs. $28.1 \%, p<0.001)$. Additionally they were more likely to have history of ischemic heart disease, diabetes, dyslipidemia, and less likely to have chronic kidney disease ( $p<0.001$ for all comparisons). The prevalence of severe LV systolic dysfunction (EF $<30 \%$ ) was higher in ACS-AHF patients. During hospital stay, ACS-AHF patients were more likely to develop shock $(p<0.001)$, recurrent heart failure $(p=0.02)$ and needed more mechanical ventilation $(p<0.001) . \beta$ blockers and Angiotensin Converting Enzyme inhibitors were used more often in ACS-AHF patients ( $p=0.001$ and, $p=0.004$ respectively). ACS- AHF patients underwent more coronary angiography and had higher prevalence of multi-vessel coronary artery disease $(p<0.001$ for all comparisons). The unadjusted hospital and one-month mortality were higher in ACS-AHF patients (OR $=1.6$ (1.2-2.2), $p=0.003$ and $1.4(1.0-1.9), p=0.026$ respectively). A significant interaction existed between the level of left ventricular ejection fraction and ACS-AHF status. After adjustment, ACS-AHF status was only significantly associated with hospital mortality $(\mathrm{OR}=1.6(1.1-2.4), p=0.019)$. The three-years survival following hospital discharge was not different between the two groups.

(Continued on next page)
\end{abstract}

\footnotetext{
* Correspondence: tkashour@gmail.com; tkashour@ksu.edu.sa

'Department of Cardiac Sciences, College of Medicine, King Saud University, Riyadh, Saudi Arabia

${ }^{11}$ Cardiac Sciences, King Khalid University Hospital, College of Medicine, King

Saud University, P.O. Box 7805, Riyadh 11472, Saudi Arabia

Full list of author information is available at the end of the article
} 
(Continued from previous page)

Conclusion: AHF patients presenting with ACS had worse hospital prognosis, and an equivalent long-term survival compared to AHF patients without ACS. These findings underscore the importance of timely recognition and management of AHF patients with concomitant ACS given their distinct presentation and underlying pathophysiology compared to other AHF patients.

Keywords: Heart failure complications/mortality/physiopathology, Acute coronary syndrome complications/mortality/ physiopathology, Hospital Mortality, Saudi Arabia/epidemiology, Prospective Studies

\section{Background}

Heart failure (HF) continues to be a significant cause of morbidity and mortality worldwide [1-3], and a prior history of coronary artery disease is present in over half of the acute HF (AHF) patients admitted to the hospital [4-8]. Data from acute coronary syndrome (ACS) registries indicate that ACS complicated by HF (ACS-AHF) leads to a several-fold increase in hospital mortality compared to those without AHF [9-11]. Additionally, the adverse effects of ACS-AHF appear to extend beyond hospital discharge and up to one year following the index event $[11,12]$. Moreover, a substantial proportion of hospitalized ACS patients develop AHF during their hospital course, and carries worse prognosis than those who present initially with ACS and AHF. Despite the high-risk status of ACS-AHF patients-, these patients are undertreated compared to ACS patients without AHF [13]. Although the clinical characteristics, therapies, and outcomes of ACS-AHF are well described in the context of ACS registries, i.e. in patients who present initially and overtly with ACS, little is known about the outcomes of these patients compared to the outcomes of AHF patients without concomitant ACS (NACS-AHF). AHF represents a syndrome that has a heterogeneous pathophysiology with variable outcomes. Thus, it is of interest to compare a group with unique pathophysiology and therapeutic targets such as ACS-AHF to NACS-AHF patients. Accordingly, we determined the prevalence, clinical correlates, and hospital therapies of ACS-AHF in a large contemporary HF registry. Additionally, we explored the impact of ACS presentation on hospital outcomes and on the shortand long-term mortality of patients hospitalized for AHF.

\section{Methods}

The design and rational of the HEARTS registry were described previously $[2,14]$. Briefly, HEARTS is the first prospective HF registry in Saudi Arabia and the Arab Middle East. It enrolled 2609 consecutive patients who were admitted to the hospital with a primary diagnosis of AHF. Patients younger than 18 years of age who were unable to provide consent were excluded from the study. The registry included data from 18 hospitals in different regions of Saudi Arabia between October 2009 and December 2010, with follow-up until January 2013. Six of the 18 hospitals participating in this study did not have cardiac catheterization laboratories or cardiac surgery facilities. The diagnosis of AHF was made according to the European Society of Cardiology guidelines for the diagnosis and management of acute and chronic HF [15]. For this analysis, we stratified the enrolled AHF patient population into two groups: those who had evidence of ACS concomitant with AHF at hospital presentation (ACS-AHF) vs. those without ACS (NACS-AHF). The ACS group comprised patients with ST elevation myocardial infarction (STEMI) and patients with non-ST acute coronary syndrome (NSTACS). The treating physician determined which patients had ACS based on the presenting symptoms and clinical context, on electrocardiography (ECG) findings, as well as on cardiac biomarker levels. The definitions for STEMI and NSTACS were based on the American College of Cardiology clinical data standards [16, 17]. Troponin assays were performed at initial emergency department assessment and were performed at the physicians' discretion. The assay cut-off values were determined by each participating hospital biochemistry lab according to their values for what constituted a positive troponin level. Data for 30-day, 1-year, 2-year, and 3-year all-cause mortality were obtained from each hospital by a telephone inquiry. We compared the clinical characteristics, hospital management, and adverse outcomes, as well as short-term and long-term all-cause mortality, following the index admission between the two groups. The study was approved by the institutional review board at each hospital and complied with the tenets of the Helsinki Declaration. The study was granted a waiver for consent because the study carried no more than minimal risk for the patients, the waiver do not affect adversely the rights and welfare of recruited patients and data management of the study carried no more than minimal risk to privacy of the patients and maintained high standards for confidentiality. Furthermore, verbal consent was obtained from recruited patients "out of courtesy" and to establish rapport with them.

\section{Statistical analysis}

Categorical data were summarized as absolute numbers and percentages. Numeric data were summarized as means and standard deviations (SD) or as medians and interquartile ranges. Comparisons between different groups were 
performed using the chi-square test or Fisher's exact for categorical variables and independent sample t-test or the Mann-Whitney $U$ test for continuous variables. The adjusted odds ratios were estimated using multiple logistic regression. Model adjustment was performed using the following variables: age, sex, history of HF, ischemic heart disease (IHD), history of percutaneous coronary intervention (PCI), history of coronary artery bypass surgery (CABG), diabetes mellitus (DM), hypertension, anemia, body mass index, estimated glomerular filtration rate (eGFR) as calculated by the chronic kidney disease epidemiology collaboration equation (CKD-EPI) [18], systolic blood pressure, diastolic blood pressure, heart rate, AHF type (de novo and acute on chronic HF), and LV systolic dysfunction. A multiple logistic regression model with stepwise selection and backward elimination was used to identify predictors of 3-year mortality, and a $5 \%$ significance level was used to remain in the model. Logistic regression with an interaction term was used to test the statistical significance of interactions between selected study groups, and we estimated the strength of the associations of these groups using odds ratios with $95 \%$ confidence intervals. Kaplan-Meier analysis was used to plot the cumulative survival, and differences between groups were assessed by the log-rank test. All analyses were performed using SAS/STAT software, version 9.2 (SAS Institute Inc., Cary, NC, USA) and R (Foundation for Statistical Computing, Vienna, Austria). A 2-sided $p$-value $<0.05$ was considered statistically significant.

\section{Results}

\section{Clinical characteristics}

Of the 2609 patients with AHF who were included in this study, 725 (27.8\%) patients had concomitant ACS (38.1\% STEMI and $61.9 \%$ NSTACS). Compared to NACS-AHF patients, patients with ACS-AHF were on average two years older $(p=0.003)$ and were more likely to be male $(p<0.001)$ (Table 1). Risk factors for atherosclerosis such as DM, hyperlipidemia, and smoking were significantly more common in ACS-AHF patients. Moreover, established vascular disease, such as IHD and peripheral arterial disease, was more frequent in ACS-AHF patients. On the other hand, $72.2 \%$ of NACS-AHF patients had a past history of HF compared to $43.5 \%$ of ACS-AHF patients $(p<0.001)$, and NACS-AHF patients more often had other comorbidities such as a past history of rheumatic heart disease, atrial fibrillation (AF), anemia, CKD, chronic liver disease, thyroid disease, and chronic lung disease.

Several differences were noted with respect to clinical presentation. A significant proportion of ACS-AHF patients presented with de novo HF (56.6\%), while $71.9 \%$ of NACS-AHF patients presented with acute on chronic HF $(p<0.001)$. NACS-AHF patients were more likely to present with AF $(21.1 \%$ vs. $7.2 \%, p<0.001)$ and to have a QRS duration $\geq 120$ ms. Significant differences between the two groups were noted for several biochemical parameters (Table 1). Notably, ACS-AHF patients had significantly higher mean random blood sugar (RBS), with the mean value $(11.43 \pm 6.2 \mathrm{mmol} / \mathrm{l})$ being in the hyperglycemia range; on the other hand, NACS-AHF patients had lower hemoglobin levels $(p<0.001$ for both comparisons). Approximately $10 \%$ of the NACS-AHF group were positive for troponin I. Serum NT-ProBNP testing was only performed in $16.7 \%$ of the total cohort, and its concentration in the ACS-AHF group was more than double that in the NACS-AHF group $(p<0.001)$. Patients with NACS-AHF were more likely to have severe left ventricular (LV) systolic dysfunction (ejection fraction (EF) $<30 \%$ ) on echocardiography compared to ACS-AHF patients. In contrast, ACS-AHF patients were more likely to have mild and moderate LV systolic dysfunction (Table 1).

\section{Hospital procedures and medical therapy}

The use of intra-aortic balloon pumps (IABP) and mechanical ventilation was higher in ACS-AHF patients (Table 2). Coronary angiography (CAG) was performed in $29.3 \%$ of the total cohort, and its performance was more than double in ACS-AHF compared to NACS-AHF patients. Single- or multi-vessel coronary disease was documented more frequently in ACS-AHF patients, while normal or nonsignificant coronary artery disease was more frequent in NACS-AHF patients. The use of intravenous nitroglycerine and dopamine was greater in ACS-AHF patients. Upon discharge, patients with ACS-AHF were more likely to be prescribed aspirin, statins, $\beta$-blockers, and angiotensinconverting enzyme (ACE) inhibitors. Conversely, the use of diuretics (furosemide and metolazone), aldosterone antagonists (AAs), hydralazine, and oral anticoagulants was higher in patients with NACS-AHF (Table 2).

\section{Hospital course}

ACS-AHF patients were more likely to suffer from shock (cardiogenic, non-cardiogenic, or both), although there was no significant difference in the rate of cardiogenic shock between the two groups $(p=0.132)$ (Table 3$)$. Additionally, the rate of recurrent HF, sepsis, and stroke or transient ischemic attack (TIA) was higher in ACS-AHF patients (Table 3). Malignant ventricular arrhythmias requiring therapy and pacing rates for brady-arrhythmias were encountered more frequently in ACS-AHF patients, but $\mathrm{AF}$ requiring therapy was more frequent in NACSAHF patients.

\section{Mortality}

Overall hospital, 30-day, 1-year, 2-year and 3-year cumulative mortality data are presented in Table 3 . The Crude hospital and 30-day mortality rates were significantly higher in ACS-AHF patients (8.8 \% vs. $5.6 \%, p=0.003$ 
Table 1 Baseline characteristics of acute heart failure patients with and without acute coronary syndrome

\begin{tabular}{|c|c|c|c|c|}
\hline & $\begin{array}{l}\text { Overall } \\
n=2609\end{array}$ & $\begin{array}{l}\text { ACS-AHF } \\
n=725(27.79 \%)\end{array}$ & $\begin{array}{l}\text { NACS-ACS } \\
n=1884(72.21 \%)\end{array}$ & $P$ value \\
\hline \multicolumn{5}{|l|}{ Demographics } \\
\hline Age, years; mean $\pm S D$ & $61.34 \pm 15$ & $62.74 \pm 13.1$ & $60.80 \pm 15.6$ & 0.003 \\
\hline Male, n (\%) & $1717(65.81)$ & $535(73.79)$ & $1182(62.74)$ & $<0.001$ \\
\hline Saudi nationality, n (\%) & $2230(85.47)$ & $546(75.31)$ & $1684(89.38)$ & $<0.001$ \\
\hline \multicolumn{5}{|l|}{ Medical history } \\
\hline Heart failure, n (\%) & $1670(64.2)$ & $315(43.5)$ & $1355(72.2)$ & $<0.001$ \\
\hline Ischemic heart disease, n (\%) & $1376(53.3)$ & $433(60.1)$ & $943(50.6)$ & $<0.001$ \\
\hline $\mathrm{PCl}, \mathrm{n}(\%)$ & $340(13.1)$ & $109(15.0)$ & $231(12.3)$ & 0.064 \\
\hline CABG, n (\%) & $261(10.0)$ & $52(7.2)$ & $209(11.1)$ & 0.003 \\
\hline Rheumatic heart disease, n (\%) & $183(7.1)$ & $4(0.5)$ & 179 (9.6) & $<0.001$ \\
\hline Atrial fibrillation, $\mathrm{n}(\%)$ & $408(15.7)$ & $37(5.1)$ & $371(19.8)$ & $<0.001$ \\
\hline ICD, n (\%) & $229(8.8)$ & $31(4.3)$ & $198(10.5)$ & $<0.001$ \\
\hline CRT, n (\%) & $85(3.3)$ & $7(0.8)$ & $78(4.1)$ & $<0.001$ \\
\hline Stroke/TIA, n (\%) & $252(9.7)$ & $67(9.2)$ & $185(9.8)$ & 0.637 \\
\hline PAD, n (\%) & $99(3.8)$ & $37(5.1)$ & $62(3.3)$ & 0.034 \\
\hline Anemia, n (\%) & $1166(44.9)$ & $301(41.7)$ & $865(46.2)$ & 0.043 \\
\hline Chronic lung disease, n (\%) & $185(7.1)$ & $37(5.1)$ & $148(7.9)$ & 0.013 \\
\hline Chronic kidney disease, n (\%) & $771(29.7)$ & $163(22.5)$ & $608(32.4)$ & $<0.001$ \\
\hline Liver disease, n (\%) & $91(3.5)$ & $9(1.2)$ & $82(4.4)$ & $<0.001$ \\
\hline Thyroid disorder, n (\%) & $172(6.8)$ & $28(4.0)$ & $144(7.9)$ & $<0.001$ \\
\hline \multicolumn{5}{|l|}{ Risk factors for atherosclerosis } \\
\hline Smoking, n (\%) & $467(17.9)$ & $182(25.1)$ & $285(15.1)$ & $<0.001$ \\
\hline Hypertension, n (\%) & $1831(70.6)$ & $506(70.8)$ & $1325(70.5)$ & 0.914 \\
\hline Dyslipidemia, n (\%) & $894(36.4)$ & $289(42.7)$ & $605(34.0)$ & $<0.001$ \\
\hline Diabetes mellitus, n (\%) & $1668(64.1)$ & $518(72.0)$ & $1150(61.1)$ & $<0.001$ \\
\hline \multicolumn{5}{|l|}{ Clinical parameters on presentation } \\
\hline Acute de novo HF, n (\%) & $939(36.0)$ & $410(56.5)$ & $529(28.1)$ & $<0.001$ \\
\hline Acute on chronic HF, n (\%) & $1670(64.0)$ & $315(43.4)$ & $1355(71.9)$ & \\
\hline $\mathrm{BMl}, \mathrm{kg} / \mathrm{m}^{2} ;$ mean $\pm \mathrm{SD}^{*}$ & $29.16 \pm 6.7$ & $28.12 \pm 5.4$ & $29.55 \pm 7.1$ & $<0.001$ \\
\hline $\mathrm{SBP}$, mean $\pm \mathrm{SD}$ & $128.7 \pm 31.3$ & $126.6 \pm 29.8$ & $129.5 \pm 31.9$ & 0.038 \\
\hline $\mathrm{DBP}$, mean $\pm \mathrm{SD}$ & $74.10 \pm 17.9$ & $73.67 \pm 17.1$ & $74.26 \pm 18.2$ & 0.454 \\
\hline $\mathrm{HR}$, mean $\pm \mathrm{SD}$ & $88.8 \pm 21.0$ & $89.7 \pm 19.1$ & $88.5 \pm 21.7$ & 0.185 \\
\hline \multicolumn{5}{|l|}{ Investigations } \\
\hline \multicolumn{5}{|l|}{ Electrocardiography } \\
\hline Atrial fibrillation/flutter, n (\%) & $449(17.2)$ & $52(7.2)$ & $397(21.1)$ & $<0.001$ \\
\hline QRS $\geq 120$ msec, n (\%) & $389(14.9)$ & $68(9.4)$ & $321(17.1)$ & $<0.001$ \\
\hline LBBB, n (\%) & $305(11.7)$ & $62(8.5)$ & $243(12.9)$ & 0.002 \\
\hline \multicolumn{5}{|l|}{ Biochemical parameters } \\
\hline Sodium, mmol/L; mean \pm SD & $135.1 \pm 5.3$ & $135.0 \pm 5.4$ & $135.2 \pm 5.3$ & 0.322 \\
\hline Potassium, $\mathrm{mmol} / \mathrm{L} ;$ mean $\pm \mathrm{SD}$ & $4.3 \pm 0.7$ & $4.2 \pm 0.7$ & $4.3 \pm 0.7$ & 0.644 \\
\hline Urea, $\mu \mathrm{mol} / \mathrm{L} ;$ mean $\pm S D$ & $11.87 \pm 9.1$ & $11.11 \pm 8.4$ & $12.16 \pm 9.3$ & 0.008 \\
\hline Creatinine, $\mu \mathrm{mol} / \mathrm{L}$; median $(\mathrm{IQR}]$ & $109.0(70.0)$ & $109.0(62.0)$ & $109.0(73.0)$ & 0.923 \\
\hline eGFR, ml/min/1.73 m²; median (IQR) & $57.28(43.5)$ & $56.32(41.9)$ & $57.82(44.1)$ & 0.444 \\
\hline
\end{tabular}


Table 1 Baseline characteristics of acute heart failure patients with and without acute coronary syndrome (Continued)

\begin{tabular}{|c|c|c|c|c|}
\hline Hemoglobin, $\mathrm{g} / \mathrm{dL}$; mean $\pm \mathrm{SD}$ & $12.43 \pm 2.2$ & $12.76 \pm 2.3$ & $12.31 \pm 2.2$ & $<0.001$ \\
\hline $\mathrm{RBS}, \mathrm{mmol} / \mathrm{L} ;$ mean $\pm \mathrm{SD}$ & $10.01 \pm 5.7$ & $11.43 \pm 6.2$ & $9.45 \pm 5.4$ & $<0.001$ \\
\hline NT-Pro-BNP, pmol/L; n (\%) & $435(16.7)$ & $101(13.9)$ & $334(17.7)$ & 0.019 \\
\hline NT-Pro-BNP, pmol/L; median (IQR) & $675.0(668)$ & $999.0(1679)$ & $631.5(684)$ & $<0.001$ \\
\hline Positive troponin, n (\%) & $867(37.4)$ & $693(98.6)$ & $174(10.8)$ & $<0.001$ \\
\hline \multicolumn{5}{|l|}{ Echocardiography } \\
\hline Left ventricular EF >55 \%, n (\%) & $341(13.7)$ & $50(7.2)$ & $291(16.2)$ & $<0.001$ \\
\hline Left ventricular EF 40-54.9\% & $334(13.4)$ & $113(16.2)$ & $221(12.3)$ & $<0.001$ \\
\hline Left ventricular EF 30-9.9\% & $632(25.3)$ & $258(37.1)$ & $374(20.8)$ & $<0.001$ \\
\hline Left ventricular EF <30 \% & $1187(47.6)$ & $275(39.5)$ & $912(50.7)$ & $<0.001$ \\
\hline
\end{tabular}

Abbreviations: ACS-AHF acute coronary syndrome with acute heart failure, $A C S-N A S C$ no acute coronary syndrome with acute heart failure, $B M I$ body mass index, $B N P$ brain natriuretic peptide, $C A B G$ coronary artery bypass surgery, $C R T$ cardiac resynchronization therapy, DBP diastolic blood pressure, $E F$ ejection fraction, eGFR estimated glomerular filtration rate, $H R$ heart rate, $I C D$ internal cardiac defibrillator, $L B B B$ left bundle branch block, $P A D$ peripheral artery disease, $P C I$ percutaneous coronary intervention, RBS random blood sugar, SD standard deviation, SBP systolic blood pressure, TIA transient ischemic attack

and $10.1 \%$ vs. $7.4 \%, p=0.04$, respectively), while there were no differences in the 1-, 2-, or 3-year cumulative mortality rates between the two groups.

The unadjusted hospital and 30-day mortality rates were significantly higher in ACS-AHF patients $(\mathrm{OR}=1.6$ (95\% CI, 1.2-2.2), $p=0.003$ and 1.40 (95 \% CI, 1.0-1.9), $p=0.026$, respectively) (Table 4). After adjustment for important demographic characteristics, past vascular history, important comorbidity risk factors for atherosclerosis, renal function, and LV dysfunction, ACS-AHF was only predictive of hospital mortality $(\mathrm{OR}=1.61$ (95\% CI, 1.1-2.4), $p=0.019$ ) (Table 4).

We looked at the interaction between ACS that was concomitant with AHF and hospital mortality in several important clinical groups, including AHF type (de novo and acute on chronic), age groups ( $\geq$ or $<65$ years of age), and LVEF level ( $\geq$ or $<40 \%$ ). AHF with ACS was a predictor of hospital mortality across all selected groups; however, its predictive power was heterogeneous, depending on the LVEF cut-off (for $\mathrm{EF}<40 \%$, OR $=1.9$ (95\% CI, 1.3-28) and for $\mathrm{EF} \geq 40 \%$, OR $=0.6$ (95\% CI 0.2-1.3), $p=0.02$ for the interaction) (Fig. 1).

The 3-year survival of ACS-AHF and NACS-AHF patients was not significantly different (log-rank test, $p=$ 0.67) (Fig. 2a). There was no survival difference between AHF patients presenting with STEMI or NSACS (Fig. 2b). The survival of patients with ACS-AHF and LVEF $<40 \%$ was significantly lower than that of patients with LVEF $>40 \%$ (log-rank test, $p=0.001)$; conversely, no survival difference was noted in patients with NACSAHF with EF above or below 40 \% (Fig. 3a and b). Although an $\mathrm{EF}<40 \%$ seemed to have a similar impact on survival in the two groups, ACS-AHF patients had significantly higher survival if the EF was $\geq 40 \%$ compared to NACS-AHF patients with the same EF cut-off (log-rank test, $p=0.005$ ) (Fig. 3c and d).
Because it was clear that the two heart failure groups (ACS-AHF and NACS-AHF) were different, we sought to determine whether the two groups have similar or different predictors of long-term mortality. Therefore, we used logistic regression analysis to identify the 3-year independent predictors of mortality in the two groups. The independent predictors of mortality in ACS patients were age, eGFR, heart rate, and LV systolic function. For patients with no ACS, the independent predictors of mortality were age, DM, hypertension, history of stroke/ transient ischemic attacks, RBS, systolic blood pressure, serum urea, and hemoglobin (Table 5).

\section{Discussion}

Our study is one of a few that compare the outcomes of patients admitted to the hospital with AHF and concomitant ACS to patients with AHF and no ACS in the context of a contemporary HF registry. Approximately a third of the registry population that was admitted with AHF had concomitant ACS, which is in accordance with several previous reports $[8,19-21]$. We found that AHF with ACS is a distinct entity with respect to clinical presentation, clinical correlates, and hospital outcomes. ACS-AHF patients were older than NACS-AHF patients and were at higher risk of cardiovascular events by virtue of their past vascular history and risk factors, notably the astonishingly high DM rates. However, they had far fewer comorbidities and were more likely to be HF naïve. This is in stark contrast to the NACS-AHF group, in which more than $70 \%$ had chronic HF.

The main finding of our study was that ACS-AHF patients had higher hospital mortality as well as higher hospital adverse cardiovascular outcomes. Notably, the intermediate and long-term mortality was not different compared to NACS-AHF patients. To our knowledge, only two published reports have addressed the outcomes 
Table 2 Hospital procedures, therapies, and discharge medications in acute heart failure patients with or without ACS

\begin{tabular}{|c|c|c|c|c|}
\hline & $\begin{array}{l}\text { Overall } \\
n=2609\end{array}$ & $\begin{array}{l}\text { ACS-AHF } \\
n=725 \text { (27.79 \%) }\end{array}$ & $\begin{array}{l}\text { NACS-ACS } \\
n=1884(72.21)\end{array}$ & $P$ value \\
\hline \multicolumn{5}{|l|}{ Hospital procedures and therapies } \\
\hline IV nitroglycerine, n (\%) & $725(27.8)$ & $397(54.8)$ & $328(17.4)$ & $<0.001$ \\
\hline Dopamine, n (\%) & $468(17.9)$ & $156(21.5)$ & $312(16.6)$ & 0.003 \\
\hline Invasive ventilation (\%) & $289(11.1)$ & $106(14.6)$ & $183(9.7)$ & $<0.001$ \\
\hline IABP, n (\%) & $86(3.3)$ & $57(7.9)$ & $29(1.5)$ & $<0.001$ \\
\hline Cardiac pacing, n (\%) & $36(1.38)$ & $18(2.48)$ & $18(0.96)$ & 0.003 \\
\hline Hospital ICD, n (\%) & $150(5.75)$ & $32(4.41)$ & $118(6.26)$ & 0.069 \\
\hline Hospital CRT, n (\%) & $68(2.61)$ & $9(1.24)$ & $59(3.13)$ & 0.007 \\
\hline CAG performed, $n(\%)$ & $764(29.3)$ & $338(46.6)$ & $426(22.6)$ & $<0.001$ \\
\hline Normal coronaries, n (\%) & $183(24.0)$ & $9(2.7)$ & $174(40.9)$ & $<0.001$ \\
\hline Non-significant CAD & $82(10.7)$ & $14(4.1)$ & $68(16.0)$ & $<0.001$ \\
\hline Single-vessel CAD, n (\%) & $105(13.7)$ & $56(16.6)$ & 49 (11.5) & 0.043 \\
\hline Double-vessel CAD, n (\%) & $116(15.2)$ & $77(22.8)$ & $39(9.2)$ & $<0.001$ \\
\hline LM or three-vessel CAD, n (\%) & $263(34.4)$ & $179(53.0)$ & $84(19.7)$ & $<0.001$ \\
\hline \multicolumn{5}{|l|}{ Discharge medications } \\
\hline Aspirin, n (\%) & 1989 (76.2) & $633(87.3)$ & $1356(72.0)$ & $<0.001$ \\
\hline Warfarin, n (\%) & $484(18.5)$ & $56(7.7)$ & $428(22.7)$ & $<0.001$ \\
\hline Statin, n (\%) & $1813(69.5)$ & $605(83.4)$ & $1208(64.1)$ & $<0.001$ \\
\hline Lasix, n (\%) & $2048(78.5)$ & $546(75.3)$ & $1502(79.7)$ & 0.014 \\
\hline Metolazone, n (\%) & $115(4.4)$ & $17(2.3)$ & $98(5.2)$ & 0.001 \\
\hline Hydralazine, n (\%) & $300(11.5)$ & $61(8.4)$ & $239(12.7)$ & 0.002 \\
\hline Long-acting nitrates, n (\%) & $252(9.7)$ & $103(14.2)$ & $149(7.9)$ & $<0.001$ \\
\hline Amiodarone, n (\%) & $75(2.9)$ & $14(1.9)$ & $61(3.2)$ & 0.074 \\
\hline Beta-blockers, n (\%) & $2180(83.0)$ & $635(87.6)$ & $1545(82.0)$ & $<0.001$ \\
\hline ACEI, n (\%) & $1554(59.6)$ & $463(63.9)$ & $1091(57.9)$ & 0.006 \\
\hline ARBI, n (\%) & $388(14.9)$ & $95(13.1)$ & $293(15.5)$ & 0.115 \\
\hline $\mathrm{AA}, \mathrm{n}(\%)$ & 999 (38.4) & $191(26.3)$ & $808(42.9)$ & $<0.001$ \\
\hline
\end{tabular}

Abbreviations: $A A$ aldosterone antagonist, $A C E l$ angiotensin-converting enzyme inhibitor, ACS-AHF acute coronary syndrome with acute heart failure, ACS-NASC no acute coronary syndrome with acute heart failure, $A R B I$ angiotensin receptor blocker, CAG coronary angiography, $C R T$ cardiac resynchronization therapy, $I A B P$ intra-aortic balloon pump, ICD internal cardiac defibrillator, $I V$ intravenous, $L M$ left main

of a comparable cohort. Our findings are in accordance with the findings of the Finnish Acute Heart Failure Study (FINN-AKVA) with respect to a higher risk of mortality in the short-term and an equivalent risk on the long-term but stand apart from another report that found that the long -term survival is lower in ACS-AHF patients [22, 23]. A few reports have highlighted the unfavorable long-term outcome of acute on chronic HF compared to de novo HF, including a report from our group [24-27]. Yet patients with ACS-AHF in our study, the majority of whom had de novo AHF, were not only at higher risk for hospital adverse cardiovascular outcomes but also had similar long-term survival rates compared to patients with NACS-AHF who predominantly presented with acute on chronic HF. The equivalent long-term survival between the two groups is a somber reality and underscores the excessive risk of mortality beyond hospital discharge and up to three years, presumably because of the older age of the ACS-AHF group, and the extensive coronary artery disease documented in their diagnostic CAG.

ACS concomitant with AHF is an independent predictor of mortality, and its detrimental effect appeared to be consistent across several selected patient subgroups. However, this effect was heterogeneous, depending on the LVEF cut-off that was used (Fig. 1). We found that a low EF adversely impacted survival to a similar degree in AHF patients with and without ACS. Although many studies have demonstrated that HF with reduced EF (HFREF) have higher mortality compared to HF with preserved systolic function (HFPEF) [28], in our cohort this was true only in AHF patients with ACS, presumably because 
Table 3 Clinical outcomes in acute heart failure patients with or without acute coronary syndrome

\begin{tabular}{|c|c|c|c|c|}
\hline & $\begin{array}{l}\text { Overall } \\
n=2609\end{array}$ & $\begin{array}{l}\text { ACS-AHF } \\
n=725(27.79 \%)\end{array}$ & $\begin{array}{l}\text { NACS-ACS } \\
n=1884(72.21)\end{array}$ & $P$ value \\
\hline \multicolumn{5}{|l|}{ Hospital course and outcomes } \\
\hline Recurrent CHF, n (\%) & $816(31.3)$ & $251(34.6)$ & $565(30.0)$ & 0.022 \\
\hline Overall shock, n (\%) & $228(8.7)$ & $94(13.0)$ & $134(7.1)$ & $<0.001$ \\
\hline Cardiogenic, n (\%) & $169(74.1)$ & $73(77.7)$ & $96(71.6)$ & 0.132 \\
\hline Non-cardiogenic, n (\%) & $22(9.6)$ & $11(11.7)$ & $11(8.2)$ & \\
\hline Mixed, n (\%) & $37(16.2)$ & $10(10.6)$ & $27(20.1)$ & \\
\hline VT/VF requiring therapy, n (\%) & $110(4.2)$ & $45(6.2)$ & $65(3.4)$ & 0.002 \\
\hline AF requiring therapy, $\mathrm{n}(\%)$ & $156(6.0)$ & $25(3.4)$ & $131(6.9)$ & $<0.001$ \\
\hline Sepsis, n (\%) & $196(7.5)$ & $68(9.4)$ & $128(6.8)$ & 0.025 \\
\hline Major bleeding, n (\%) & $38(1.5)$ & $14(1.9)$ & $24(1.4)$ & 0.209 \\
\hline Stroke/TIA, n (\%) & $48(1.8)$ & $23(3.2)$ & $25(1.3)$ & 0.002 \\
\hline Hospital stay, days; mean \pm SD & $12.3 \pm 14.6$ & $13.1 \pm 15.38$ & $12.0 \pm 14.3$ & 0.083 \\
\hline Hospital stay, days; median (IQR) & $8.0(9.0)$ & $8.0(10.0)$ & $8.0(9.0)$ & 0.111 \\
\hline \multicolumn{5}{|l|}{ All-cause mortality } \\
\hline Hospital, n (\%) & $170(6.5)$ & $64(8.8)$ & $106(5.6)$ & 0.003 \\
\hline 1 month, n (\%) & $212(8.1)$ & $73(10.1)$ & $139(7.4)$ & 0.044 \\
\hline 1 year, n (\%) & 509 (19.5) & $147(20.3)$ & 362 (19.2) & 0.568 \\
\hline 2 years, n (\%) & $615(23.6)$ & $171(23.6)$ & $444(23.6)$ & 0.680 \\
\hline 3 years, n (\%) & $635(24.3)$ & $175(24.1)$ & $460(24.4)$ & 0.671 \\
\hline
\end{tabular}

Abbreviations: ACS-AHF acute coronary syndrome with acute heart failure, ACS-NASC no acute coronary syndrome with acute heart failure, $V T$ ventricular tachycardia, VF ventricular fibrillation, $A F$ atrial fibrillation, TIA transient ischemic attacks

HFPEF patients without ACS in our patient cohort were at very high risk of mortality. Another intriguing finding is that HFPEF patients with no ACS showed significantly lower survival compared to their counterparts with ACS. The reason for the lower survival of HFPEF patients without ACS is unclear, but it is plausible that the lower survival can be explained by the higher prevalence of both cardiac and non-cardiac comorbidities compared to patients with ACS (data not shown). The prognosis of HFPEF patients is strongly linked to underlying non-cardiac comorbidities, such as chronic lung or liver disease [29, 30].
Additionally, anti-HF therapies can often be countered or blunted by pharmacological agents used for treating these non-cardiac comorbidities [29, 30].

Our data highlight several important differences in hospital therapies in the two groups. The high use of IABPs and inotropes in ACS-AHF patients likely reflects the high rates of shock, though it is important to note that the rate of cardiogenic shock was not different between the two groups, contrary to a previous report [22]. The use of nitroglycerine, aspirin, statins, and $\beta$-blockers in patients with ACS-AHF is understandably high because

Table 4 Crude and adjusted hospital, short-term, and long-term outcomes in acute heart failure with concomitant ACS

\begin{tabular}{lllll}
\hline Covariate & Crude OR $(95 \% \mathrm{Cl})$ & $P$ value & Adjusted OR $(95 \% \mathrm{Cl})$ & $P$ value \\
\hline Recurrent heart failure & $1.24(1.03-1.48)$ & 0.022 & $1.66(1.33-2.06)$ & $1.85(1.31-2.60)$ \\
Overall shock & $1.95(1.47-2.57)$ & $<0.001$ & $1.87(0.98-3.56)$ & $<0.001$ \\
$\begin{array}{l}\text { Stroke/TIA } \\
\text { All-cause mortality }\end{array}$ & $2.44(1.37-4.32)$ & 0.002 & & 0.001 \\
Hospital & & & $1.61(1.08-2.39)$ & 0.055 \\
1-month & $1.62(1.17-2.24)$ & 0.003 & $1.36(0.9-1.95)$ & 0.019 \\
1-year & $1.40(1.04-1.89)$ & 0.026 & $1.16(0.89-1.51)$ & 0.252 \\
2-year & $1.07(0.86-1.32)$ & 0.548 & $1.10(0.85-1.40)$ & 0.462 \\
3-year & $1.00(0.81-1.22)$ & 1.000 & $1.07(0.83-1.35)$ & 0.600 \\
\hline
\end{tabular}




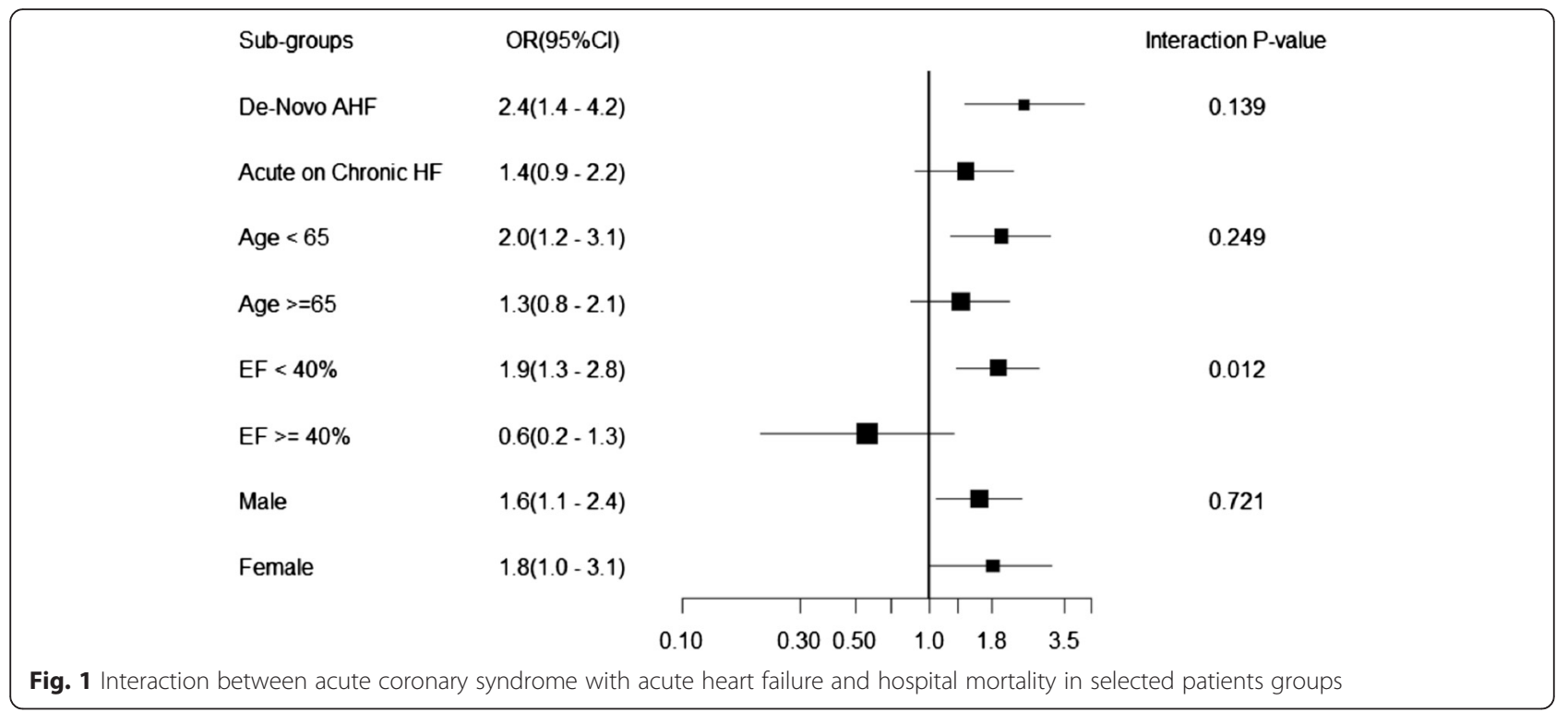

these are standard therapies for ACS and IHD in general. The lower use of ACE inhibitors in the NACS-AHF patients might be related to the significantly higher proportion of preserved EF in this group. Additionally, the use of diuretics and AAs was higher in the NACS-AHF patients. Congestive symptoms tend to be higher in patients with chronic HF, and as previously noted, acute on chronic HF was more frequent in the NACS-AHF group [22, 23, 25]. In addition, almost half the NACS-AHF cohort had severe LV systolic dysfunction, and that, along with chronic HF, could explain the higher use of AAs in NACS-AHF patients as well as the higher implantation rates of internal cardiac defibrillators/cardiac resynchronization therapy. Given the fact that the NACS-AHF group more often had a past history of $\mathrm{AF}$, as well more often had incident $\mathrm{AF}$, it is not surprising that the prescription of oral anticoagulation therapy was also high. Overall, the rate of performance of CAG was low in this cohort, and it was performed in less than half of the ACS-AHF cohort. Nonetheless, CAG was performed more than twice as often in patients with ACS-AHF than with NACS-AHF, and the finding of higher significant coronary disease in this group is to be expected. Although we did not collect data on revascularization rates, it is conceivable that these rates are even
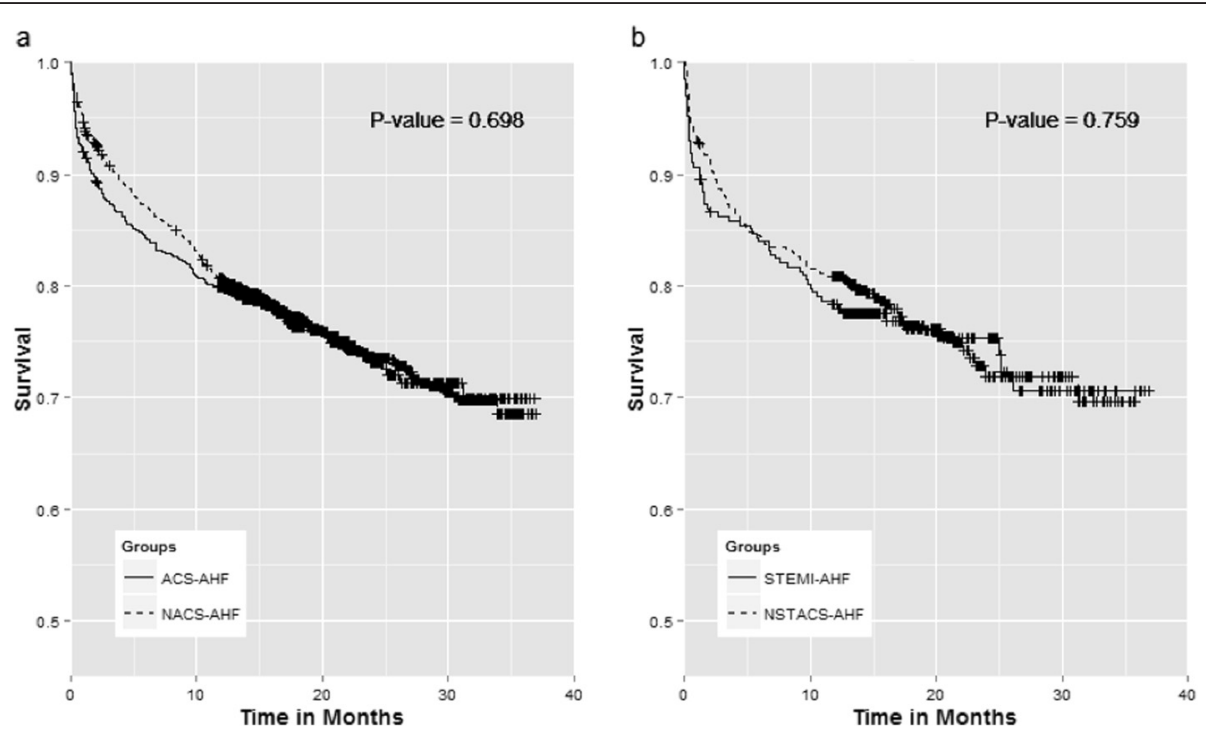

Fig. 2 Kaplan-Meier survival curves between: a acute heart failure with (solid line) and without acute coronary syndrome (dashed line), b ST elevation myocardial infarction (solid line) and Non ST acute coronary syndrome (dashed line) 

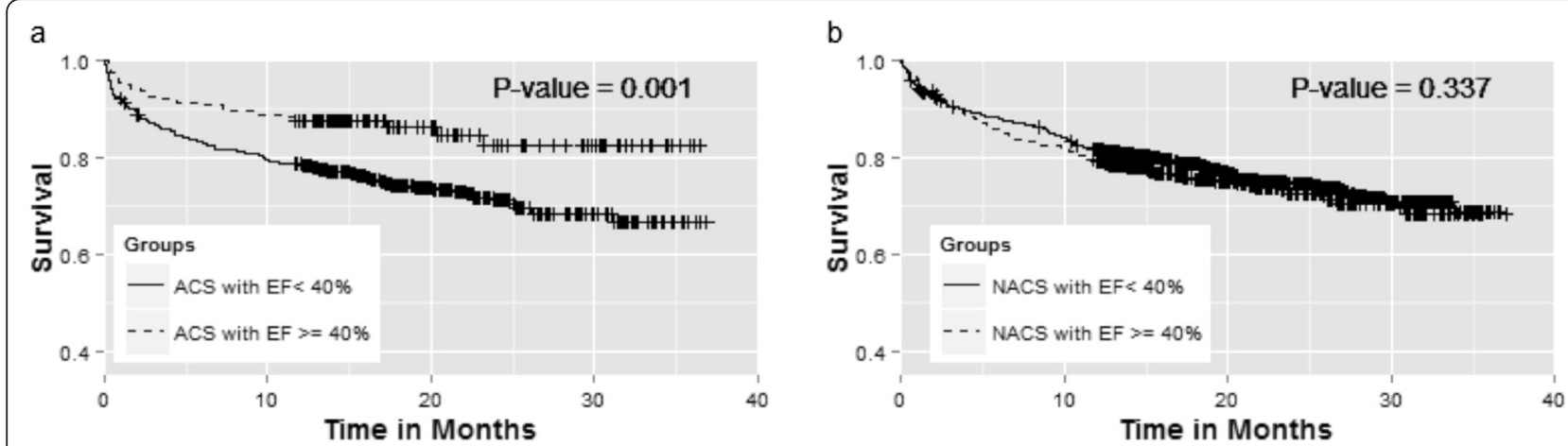

C

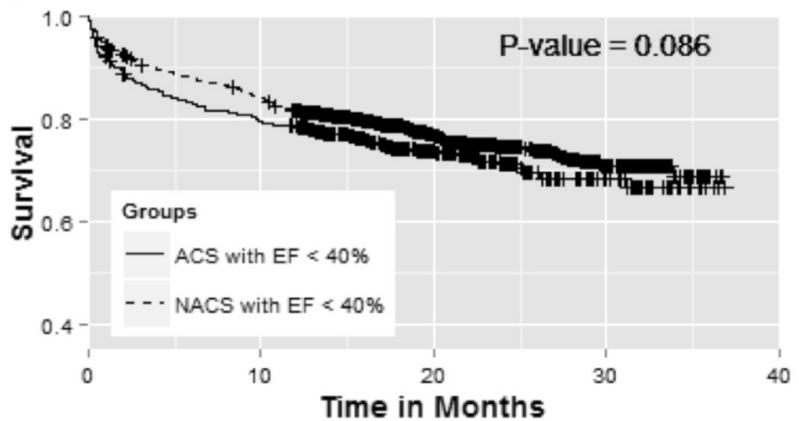

d

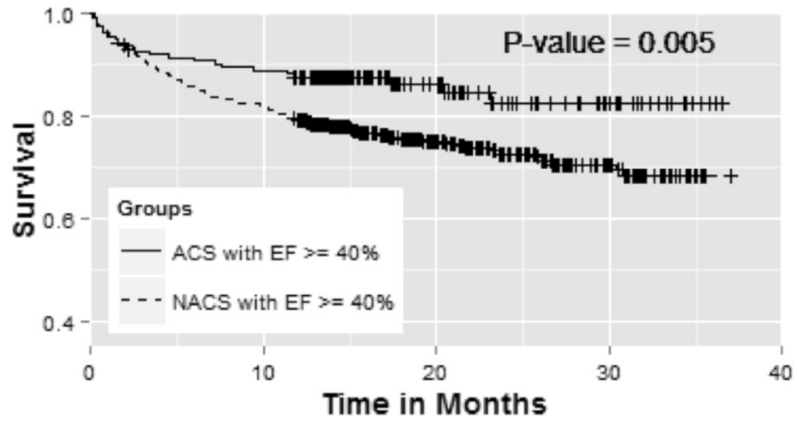

Fig. 3 Kaplan-Meier survival curves between: a Acute coronary syndrome (ACS) with ejection (EF) $<40 \%$ (solid line) and ACS with EF $\geq 40 \%$, b No ACS $<40 \%$ (solid line) and No ACS with EF $\geq 40 \%$, c ACS with EF $<40 \%$ (solid line) and no ACS with EF $<40 \%$ (dashed line), d ACS with $\geq 40 \%$ (solid line) and No ACS with EF $\geq 40 \%$ (dashed line)

Table 5 Predictors of 3-year all-cause mortality, after adjustment for multiple variates, in acute heart failure with or without acute coronary syndrome

\begin{tabular}{|c|c|c|c|c|}
\hline & Odds ratio & $\begin{array}{l}95 \% \mathrm{Cl} \\
\text { Lower bound }\end{array}$ & $\begin{array}{l}95 \% \mathrm{Cl} \\
\text { Upper bound }\end{array}$ & $P$ value \\
\hline \multicolumn{5}{|l|}{ Acute heart failure with ACS } \\
\hline Age (for every 1 year increase) & 1.02 & 1.00 & 1.04 & 0.015 \\
\hline eGFR (for every $5 \mathrm{~mL} / \mathrm{min} / 1.73 \mathrm{~m}^{2}$ decrease) & 1.09 & 1.03 & 1.16 & $<0.001$ \\
\hline HR (for every 5 beats/min increase) & 1.09 & 1.03 & 1.15 & 0.004 \\
\hline Mild LV dysfunction EF 40 \%-49.9 \% & 1.02 & 0.36 & 2.87 & 0.976 \\
\hline Moderate LV dysfunction EF 30-39.9\% & 2.37 & 0.96 & 5.82 & 0.060 \\
\hline Severe LV dysfunction EF <30 \% & 2.78 & 1.14 & 6.78 & 0.024 \\
\hline \multicolumn{5}{|l|}{ Acute heart failure without ACS } \\
\hline Age (for every 1 year increase) & 1.03 & 1.02 & 1.04 & $<0.001$ \\
\hline Diabetes mellitus & 0.61 & 0.46 & 0.83 & 0.001 \\
\hline Hypertension & 1.45 & 1.04 & 2.01 & 0.027 \\
\hline Stroke/TIA & 1.54 & 1.06 & 2.25 & 0.025 \\
\hline RBS (for every $1 \mathrm{mmol} / \mathrm{L}$ increase) & 1.03 & 1.01 & 1.06 & 0.006 \\
\hline SBP (for $1 \mathrm{mmHg}$ increase) & 0.99 & 0.99 & 1.00 & $<0.001$ \\
\hline Urea (for every $1 \mu \mathrm{mol} / \mathrm{L}$ increase) & 1.05 & 1.03 & 1.06 & $<0.001$ \\
\hline Hemoglobin (for every $1 \mathrm{~g} / \mathrm{dL}$ increase) & 0.88 & 0.83 & 0.93 & $<0.001$ \\
\hline
\end{tabular}

Abbreviations: $A C S$ acute coronary syndrome, $E F$ ejection fraction, eGFR estimated glomerular filtration rate, $L V$ left ventricular, $R B S$ random blood sugar, $S B P$ systolic blood pressure, TIA transient ischemic attacks 
lower in the context of the low rates of diagnostic CAG. Moreover, $60 \%$ of patients presenting with ACS in our cohort had a past history of IHD; therefore, it could be argued that prior knowledge of their coronary anatomy might have influenced the decision to perform CAG and subsequent revascularization if indicated. Furthermore, some physicians might have scheduled the CAG after hospital discharge when the HF symptoms would be fully resolved.

The reasons underlying the dire outlook of ACS-AHF patients are unclear. Favorable clinical outcomes in ACS depend on rapid diagnosis and risk assessment that leads to timely therapy $[17,31]$. The presentation of AHF might on certain occasions obscure concomitant ACS, which in turn could delay risk stratification and rapid treatment [32]. Unfortunately, patients with a combination of ACS and AHF tend to be undertreated and thus to undergo less invasive therapies [11]. Moreover, ischemia often leads to increased myocardial stress and cardiomyocyte damage, and NT-proBNP and troponin are two biomarkers linked to myocardial stress and damage [32]. Indeed, we found that both markers were significantly higher in the ACS-AHF group than in the NACS-AHF group.

Our findings highlight the fact that the intersection of ACS and AHF results in a unique HF entity both in terms of pathophysiology and therapeutic targets. Accordingly, future clinical trials that investigate new therapeutic agents for HF should take into account the uniqueness of this entity rather than including these groups of patients in the general pool of AHF patients.

This study has several limitations. Participation in this registry was voluntary, so selection bias cannot be excluded. Nonetheless, enrolling consecutive patients should minimize this limitation. Although the diagnosis of ACS was guided by the protocol, the diagnosis was based largely on the physician's judgment of the clinical context and presenting symptoms along with the ECG and cardiac biomarker findings. This could lead to under or over diagnosis of ACS. However, the rates of ACS in our cohort were comparable to those in previous HF registries [8, 19-21]. We did not collect data on hospital coronary revascularization, but the rate is likely to be low in view of the low performance of CAG. We also did not collect post-discharge data pertaining to re-hospitalization, compliance with medical therapy, or revascularization procedures, and these data could influence the long-term outcomes.

\section{Conclusion}

ACS-AHF patients differ from NACS-AHF patients in their baseline characteristics, baseline risk level, and cardiovascular outcomes. Future research should focus on developing timely diagnostic and therapeutic strategies to improve the outcomes of this high-risk group.

\section{Abbreviations}

ACS: acute coronary syndrome; AF: atrial fibrillation; AHF: acute heart failure; CABG: coronary artery bypass grafting; CAG: coronary angiography;

CKD-EPI: chronic kidney disease epidemiology collaboration equation;

DM: diabetes mellitus; EF: ejection fraction; eGFR: estimated glomerular

filtration rate; IABP: intraaortic balloon pump; IHD: ischemic heart disease;

NSACS: non-ST elevation acute coronary syndrome; NT-proBNP: N-terminal pro brain natriuretic peptide; OR: odds ratios; $\mathrm{PCl}$ : percutaneous intervention; SD: standard deviation; STEMI: ST elevation myocardial infarction;

TIA: transient ischemic attack.

\section{Acknowledgements}

HEARTS was co-funded by Servier and AstraZeneca, who had no role in data extraction or analysis, in the writing of the manuscript, or in the decision to submit the manuscript for publication. The College of Medicine Research

Center at King Khalid University Hospital, King Saud University, Riyadh, Saudi Arabia, provided ethics approval and partial funding (RG-1436-013).

\section{Availability of supporting data}

HEARTS database is available for public access. Interested individuals can access the database by writing to the principal investigator, Dr. Khalid AlHabib (khalidalhabib13@hotmail.com).

\section{Authors' contributions}

HA: Contributed to study design, data analysis and interpretation and writing of the manuscript. EA: Data acquisition and interpretation, critical revision of the manuscript. AU: Statistical analysis, manuscript preparation. KA: Study design, data interpretation and critical revision of the manuscript. AH: Study design, data interpretation and critical revision of the manuscript. LM: Data acquisition and critical revision of the manuscript. AAl: Data acquisition and critical revision of the manuscript. SA: Data acquisition and critical revision of the manuscript. AG: Data acquisition and critical revision of the manuscript. AM: Data acquisition and critical revision of the manuscript. GH: Data acquisition and critical revision of the manuscript. MA: Data acquisition and critical revision of the manuscript. AAb: Data acquisition and critical revision of the manuscript. WA: Data acquisition and critical revision of the manuscript. TK: Study conception and design, data analysis and interpretation and writing of the manuscript. All authors read and approved the final manuscript.

\section{Competing interests}

Dr. Khalid AlHabib received research fund from Servier and AstraZeneca companies.

\section{Consent to publish statement}

All study participants consented to publish this manuscript.

Ethics committees that approved the study

Research Ethics Committee

College of Medicine

King Saud University

P. O. Box 2925

Riyadh 11461

Kingdom of Saudi Arabia

Institutional Review Board

King Fahad Medical City

P.O. Box 59046

Riyadh 11525

Kingdom of Saudi Arabia

Institutional Review Board

King Abdulaziz University Hospital

King Abdulaziz University

P.O. Box 80200

Jeddah 21589

Kingdom of Saudi Arabia

Institutional Review Board

Prince Sultan Cardiac Center

P.O. Box 99911

Riyadh 
Kingdom of Saudi Arabia Institutional Review Board Madina Cardiac Center Khalid Ibn Al Walid Rd Al Madina Al Monaoarah 42351 Kingdom of Saudi Arabia Institutional Review Board Prince Sultan Cardiac Center Al Salmaniyah South Al Hofuf 36441 Kingdom of Saudi Arabia Institutional Review Board King Fahad General Hospital Al Mustashfa Al Am Al Andalus

Jeddah 23325

Kingdom of Saudi Arabia Institutional Review Board North West Armed Forces Hospital 4455 Telegraph $\mathrm{Rd}$

Tabuk 47512

Kingdom of Saudi Arabia

Institutional Review Board

Armed Forces Hospital Southern Region

15 King Khalid Rd

Khamis Mushait 62413

Kingdom of Saudi Arabia

Institutional Review Board

National Guard Hospital

P.O. Box 9515

Jeddah 21423

Kingdom of Saudi Arabia

\section{Author details}

'Department of Cardiac Sciences, College of Medicine, King Saud University, Riyadh, Saudi Arabia. ${ }^{2}$ King Salman Heart Center, King Fahd Medical City, Riyadh, Saudi Arabia. ${ }^{3}$ King Abdulaziz University Hospital, King Abdulaziz University, Jeddah, Saudi Arabia. ${ }^{4}$ Prince Sultan Cardiac Center, Riyadh, Saudi Arabia. ${ }^{5}$ Madina Cardiac Center, Al Madina Al Monaoarah, Saudi Arabia. ${ }^{6}$ Prince Sultan Cardiac Center, Hafouf, Saudi Arabia. ${ }^{7}$ King Fahad General Hospital, Jeddah, Saudi Arabia. ${ }^{8}$ North West Armed Forces Hospital, Tabuk, Saudi Arabia. ${ }^{9}$ Armed Forces Hospital Southern Region, Khamis Mushayt, Saudi Arabia. ${ }^{10}$ National Guard Hospital, Jeddah, Saudi Arabia. ${ }^{11}$ Cardiac Sciences, King Khalid University Hospital, College of Medicine, King Saud University, P.O. Box 7805, Riyadh 11472, Saudi Arabia.

Received: 23 October 2015 Accepted: 29 April 2016 Published online: 20 May 2016

\section{References}

1. Bleumink GS, Knetsch AM, Sturkenboom MC, Straus SM, Hofman A, Deckers JW, et al. Quantifying the heart failure epidemic: prevalence, incidence rate, lifetime risk and prognosis of heart failure The Rotterdam Study. Eur Heart J. 2004;25(18):1614-9.

2. AlHabib KF, Elasfar AA, Alfaleh H, Kashour T, Hersi A, AlBackr H, et al. Clinical features, management, and short- and long-term outcomes of patients with acute decompensated heart failure: phase I results of the HEARTS database. Eur J Heart Fail. 2014;16(4):461-9.

3. Sulaiman K, Panduranga P, Al-Zakwani I, Alsheikh-Ali AA, AlHabib KF, Al-Suwaidi J, et al. Clinical characteristics, management, and outcomes of acute heart failure patients: observations from the Gulf acute heart failure registry (Gulf CARE). Eur J Heart Fail. 2015;17(4):374-84

4. Cleland JG, Swedberg K, Follath F, Komajda M, Cohen-Solal A, Aguilar JC, et al. The EuroHeart Failure survey programme- a survey on the quality of care among patients with heart failure in Europe. Part 1: patient characteristics and diagnosis. Eur Heart J. 2003;24(5):442-63.

5. Fonarow GC, Abraham WT, Albert NM, Stough WG, Gheorghiade M Greenberg BH, et al. Factors identified as precipitating hospital admissions for heart failure and clinical outcomes: findings from OPTIMIZE-HF. Arch Intern Med. 2008;168(8):847-54
6. Parenica J, Spinar J, Vitovec J, Widimsky P, Linhart A, Fedorco M, et al. Long-term survival following acute heart failure: the Acute Heart Failure Database Main registry (AHEAD Main). Eur J Intern Med. 2013;24(2):151-60.

7. Purek L, Laule-Kilian K, Christ A, Klima T, Pfisterer ME, Perruchoud AP, et al. Coronary artery disease and outcome in acute congestive heart failure. Heart (British Cardiac Society). 2006:92(5):598-602.

8. Nieminen MS, Brutsaert D, Dickstein K, Drexler H, Follath F, Harjola VP, et al. EuroHeart Failure Survey II (EHFS II): a survey on hospitalized acute heart failure patients: description of population. Eur Heart J. 2006;27(22):2725-36.

9. Haim M, Battler A, Behar S, Fioretti PM, Boyko V, Simoons ML, et al. Acute coronary syndromes complicated by symptomatic and asymptomatic heart failure: does current treatment comply with guidelines? Am Heart J. 2004;147(5):859-64.

10. Albackr HB, Alhabib KF, Ullah A, Alfaleh $H$, Hersi A, Alshaer $F$, et al. Prevalence and prognosis of congestive heart failure in Saudi patients admitted with acute coronary syndrome (from SPACE registry). Coron Artery Dis. 2013;24(7):596-601.

11. Steg PG, Dabbous OH, Feldman $\sqcup$, Cohen-Solal A, Aumont MC, Lopez-Sendon J, et al. Determinants and prognostic impact of heart failure complicating acute coronary syndromes: observations from the Global Registry of Acute Coronary Events (GRACE). Circulation. 2004:109(4):494-9.

12. Segev A, Strauss BH, Tan M, Mendelsohn AA, Lai K, Ashton T, et al. Prognostic significance of admission heart failure in patients with non-ST-elevation acute coronary syndromes (from the Canadian Acute Coronary Syndrome Registries). Am J Cardiol. 2006;98(4):470-3.

13. Kashani A, Giugliano RP, Antman EM, Morrow DA, Gibson CM, Murphy SA, et al. Severity of heart failure, treatments, and outcomes after fibrinolysis in patients with ST-elevation myocardial infarction. Eur Heart J. 2004;25(19):1702-10.

14. AlHabib KF, Elasfar AA, AlBackr H, AlFaleh H, Hersi A, AlShaer F, et al. Design and preliminary results of the heart function assessment registry trial in Saudi Arabia (HEARTS) in patients with acute and chronic heart failure. Eur J Heart Fail. 2011;13(11):1178-84

15. Dickstein K, Cohen-Solal A, Filippatos G, McMurray JJ, Ponikowski P, PooleWilson PA, et al. ESC guidelines for the diagnosis and treatment of acute and chronic heart failure 2008: the Task Force for the diagnosis and treatment of acute and chronic heart failure 2008 of the European Society of Cardiology. Developed in collaboration with the Heart Failure Association of the ESC (HFA) and endorsed by the European Society of Intensive Care Medicine (ESICM). Eur J Heart Fail. 2008;10(10):933-89.

16. Cannon CP, Battler A, Brindis RG, Cox JL, Ellis SG, Every NR, et al. American College of Cardiology key data elements and definitions for measuring the clinical management and outcomes of patients with acute coronary syndromes. A report of the American College of Cardiology Task Force on Clinical Data Standards (Acute Coronary Syndromes Writing Committee). J Am Coll Cardiol. 2001;38(7):2114-30.

17. Amsterdam EA, Wenger NK, Brindis RG, Casey Jr DE, Ganiats TG, Holmes Jr DR, et al. 2014 AHA/ACC Guideline for the Management of Patients With Non-ST-Elevation Acute Coronary Syndromes: A Report of the American College of Cardiology/American Heart Association Task Force on Practice Guidelines. J Am Coll Cardiol. 2014;64(24):e139-228.

18. Levey AS, Stevens LA, Schmid $\mathrm{CH}$, Zhang $\mathrm{YL}$, Castro 3rd AF, Feldman $\mathrm{HI}$, et al. A new equation to estimate glomerular filtration rate. Ann Intern Med. 2009;150(9):604-12.

19. Siirila-Waris K, Lassus J, Melin J, Peuhkurinen K, Nieminen MS, Harjola VP. Characteristics, outcomes, and predictors of 1-year mortality in patients hospitalized for acute heart failure. Eur Heart J. 2006;27(24):3011-7.

20. Harjola VP, Follath F, Nieminen MS, Brutsaert D, Dickstein K, Drexler $H$, et al. Characteristics, outcomes, and predictors of mortality at 3 months and 1 year in patients hospitalized for acute heart failure. Eur J Heart Fail. 2010;12(3):239-48.

21. Parissis JT, Rafouli-Stergiou P, Mebazaa A, Ikonomidis I, Bistola V, Nikolaou M, et al. Acute heart failure in patients with diabetes mellitus: clinical characteristics and predictors of in-hospital mortality. Int J Cardiol. 2012;157(1):108-13.

22. Tarvasmaki T, Harjola VP, Nieminen MS, Siirila-Waris K, Tolonen J, Tolppanen H, et al. Acute heart failure with and without concomitant acute coronary syndromes: patient characteristics, management, and sunvival. J Card Fail. 2014;20(10):723-30.

23. Greenberg G, Cohen E, Garty M, lakobishvili Z, Sandach A, Behar S, et al. Outcomes of acute heart failure associated with acute coronary syndrome versus other causes. Acute Card Care. 2011;13(2):87-92.

24. AlHabib KF, Kashour T, Elasfar AA, Alfaleh H, Hersi A, Alshamiri M, et al. Long-term mortality rates in acute de novo versus acute-on-chronic heart failure: from the heart function assessment registry trial in Saudi Arabia. Angiology. 2015;66(9):837-44. 
25. Lassus JP, Siirila-Waris K, Nieminen MS, Tolonen J, Tarvasmaki T, Peuhkurinen K, et al. Long-term survival after hospitalization for acute heart failure-differences in prognosis of acutely decompensated chronic and new-onset acute heart failure. Int J Cardiol. 2013;168(1):458-62.

26. Choi DJ, Han S, Jeon ES, Cho MC, Kim JJ, Yoo BS, et al. Characteristics, outcomes and predictors of long-term mortality for patients hospitalized for acute heart failure: a report from the korean heart failure registry. Korean Circ J. 2011:41(7):363-71.

27. Zannad F, Mebazaa A, Juilliere Y, Cohen-Solal A, Guize L, Alla F, et al. Clinical profile, contemporary management and one-year mortality in patients with severe acute heart failure syndromes: The EFICA study. Eur J Heart Fail. 2006;8(7):697-705.

28. Meta-analysis Global Group in Chronic Heart Failure (MAGGIC). The survival of patients with heart failure with preserved or reduced left ventricular ejection fraction: an individual patient data meta-analysis. Eur Heart J. 2012;33(14):1750-7.

29. Lund LH, Donal E, Oger E, Hage C, Persson H, Haugen-Lofman I, et al. Association between cardiovascular vs. non-cardiovascular co-morbidities and outcomes in heart failure with preserved ejection fraction. Eur J Heart Fail. 2014;16(9):992-1001.

30. Chan MM, Lam CS. How do patients with heart failure with preserved ejection fraction die? Eur J Heart Fail. 2013;15(6):604-13.

31. O'Gara PT, Kushner FG, Ascheim DD, Casey Jr DE, Chung MK, de Lemos JA, et al. 2013 ACCF/AHA guideline for the management of ST-elevation myocardial infarction: a report of the American College of Cardiology Foundation/American Heart Association Task Force on Practice Guidelines. J Am Coll Cardiol. 2013;61(4):e78-140.

32. Drexler B, Heinisch C, Balmelli C, Lassus J, Siirila-Waris K, Arenja N, et al. Quantifying cardiac hemodynamic stress and cardiomyocyte damage in ischemic and nonischemic acute heart failure. Circ Heart Fail. 2012;5(1):17-24

\section{Submit your next manuscript to BioMed Central and we will help you at every step:}

- We accept pre-submission inquiries

- Our selector tool helps you to find the most relevant journal

- We provide round the clock customer support

- Convenient online submission

- Thorough peer review

- Inclusion in PubMed and all major indexing services

- Maximum visibility for your research

Submit your manuscript at www.biomedcentral.com/submit 